\title{
The potential risks of standardising China's translated foreign affairs discourse
}

Edition 7, 2021

Assistant Professor Bei Hu

DOI: 10.37839/MAR2652-550X7.10

For Westerners who have only rudimentary Chinese proficiency, daily life in China can be filled with confusing phrases. Bewildering English public signs such as 'slip and fall down carefully' in a restroom with wet floors and 'slobber-in chicken' in a local restaurant's menu sound awkward to Western ears. The laughter they elicit can be humiliating to Chinese people and generally hurt national pride. This has led to a growing zeal at government level to improve English expression.

The demand to correct English public signs has coincided with China's increasing experience hosting large international events which attract large numbers of foreign visitors. To prepare for the 2010 Shanghai Expo, the Shanghai Commission for the Management of Language Use recruited over 600 volunteers to help hundreds of restaurants correct odd-sounding English menus and fix more than 10,000 public signs. The campaign was in parallel with Beijing's herculean effort to improve English signage in placards for the 2008 Summer Olympics and the upcoming 2022 Winter Olympics.

However, what really interests me is the Chinese government's attempts to standardise translation in many contexts, including foreign affairs discourse, and whether this produces the best results.

The Government's Guidelines for the Use of English in Public Service Areas in China, which was launched in 2017, takes a prescriptive position in relation to the English 
translations of specific public signs at restaurants, airports, hotels and banks. The underlying logic is that one Chinese item should correspond to one English equivalent, echoing the idea of a one-to-one equivalence in technical translation that was largely developed in the language localisation industry. This is a field where the translator is rarely asked to translate a whole source text from scratch-as one does for literary work-but is more likely to work with standardised databases and glossaries.

Standardised translation has the potential to reduce translation errors, particularly when qualified translators are in short supply. However, technical translations as a form of natural equivalence (for example, in the world of Microsoft, the English term “desktop” must be translated as “桌面 (zhuo mian)” in Chinese, and vice versa), only work in a context-free situation.

It is intriguing to speculate whether attempts to standardise translation is the the best practice in Chinese foreign affairs discourse. In 2014, a government-sponsored database on standardised translation, China Keywords, was jointly initiated by the China Foreign Languages Publishing Administration (CFLPA), the China Academy of Translation and the Translators Association of China. In late 2018, the China Academy of Translation embarked on a similar endeavour with the CFLPA, launching a multilingual corpus called the Standardised Terminology Database of Foreign Affairs Discourse with Chinese Characteristics. Both databases aim to provide official translations of Chinese political slogans and expressions, serving as a standard for authoritative source-target equivalents. For example, the official target text of the original text '两个一百年奋斗目标 (liang ge yi bai nian fen dou mu biao)' must be translated as 'the Two Centenary Goals'.

Interestingly, some standardised glossaries seem to move beyond phrase-based renderings into whole sentence translations, such as '[T] he system of socialism with Chinese characteristics provides the fundamental institutional guarantee for progress and development in contemporary China'. 
In the eyes of Chinese translation officials, using the standardised literal translation is an indication of the institutional translator's loyalty: both professional and ideological. To be unfaithful to the original word is considered a betrayal of loyalty to the system and presumably also to the 'spirit' of Communist ideology. The standardised glossary suggests that a plurality of interpretations is undesirable and that there is only one legitimately authoritative translation of the Chinese narratives. This tends to delegitimise any other translator interventions, such as giving explanation or tailoring the text for the reader's convenience.

Translation standardisation is seen as a solution for managing the risk of mistranslation. The standardised translation database, for instance, states that its aim is to 'tell China's story well' by providing 'authoritative translations' and disseminate 'a good Chinese voice' to international communities.

There is an explicit link between translation and the success of China's diplomacy. According to the Vice Director of the China Academy of Translation Huang Youyi, who was also the former vice director of the CFLPA: "The extent of the development of translation in China determines the extent of the development of the Belt and Road Initiative'. The underlying logic is that expensive mistakes attributed to translation errors that ultimately affect China's image are not uncommon, notably those oft-reported anecdotes concerning the mistranslations of political leaders.

Nevertheless, a standardised, source-oriented, and literal translation (sometimes in a sentence-level) comes at a price: it does not take account the situation in which the original texts are produced and the intended audience for which the translations are addressed. A source term might need to be translated in very different situations for different readers with different expectations.

For instance, President Xi Jinping's political remarks are heavily laden with Chinese idioms and classical lore, which epitomise the government's agenda for 'great rejuvenation' to restore China to its ancient prominence and glory. According to the Standardised Terminology Database of Foreign Affairs Discourse with Chinese 
Characteristics, the president's idiomatic expression 打铁还须自身硬 (da tie hai xu zi shen ying) should be translated as '[i]t takes good iron to make good products'. The president used this phrase to specifically refer to his crusade against corruption and cronyism within the Chinese Communist Party. However, perhaps not every reader in any situation could correctly digest the context-dependent, audience-based and situational translation. Some may also wonder to what extent ordinary Englishspeaking readers understand what 'Four-Pronged strategy' means - a broad policy outline that attempts to address issues regarding social welfare, economic reform, China's legal system and Xi's anti-corruption campaign.

The belief that 'literalism-equals-faithfulness' in translation as a measure of the translator's fidelity to the original text, in effect showing loyalty to the political regime, also comes with some doubt. The word-for-word translation of 全面小康 (quan mian xiao kang) as 'a moderately prosperous society in all respects' may raise some eyebrows: after all, how can a society be 'moderately prosperous?' Is that society rich or only somewhat rich? This jargon was faithfully adopted by the Chinese official interpreter at the United States-China talks in Alaska in early 2021, where top Chinese and the United States diplomats clashed in heated exchange over foreign affairs. There is also no shortage of historical examples of literal translations that create misunderstandings that mislead and distort the original message, albeit unintentionally. For instance, the Chinese government used to describe its publicity and external communication as 'propaganda', which is a literal translation of the Chinese original term '宣传 (xuan chuan)'. But its negative connotation in English is unwanted by the government.

It should be noted that China does not have a monopoly on source-oriented institutional translation. European Union translations have also been found not to address target-language readers but are instead produced for the political agendas of the source institution. The monolingual Chinese website of China's standardised database further indicates that the intended reader of the standardised, literal translation is not just target-language audiences but institutional translators, internal stakeholders and domestic readers. 
The source-oriented translation norms of Chinese foreign affairs discourse have been recently challenged internally, albeit in a mild way. Some more open-minded translation officials have proposed the three principles of adherence (" 三贴近, san tie jin'), in which the audience's information needs and target-culture conventions are regarded as critical. I applaud the attempts to give visibility to prospective target-language readers.

What has remained largely unshaken, however, is the endeavour to build a standardised database that delegitimises translators as active meditators who can adapt to a real-life communicative situation.

The question is whether the endeavour to control the method of translating political terms (literally or freely) always maximises the communicative effect of a country's foreign affairs discourse and its carefully managed international identity. My contention is that foreign affairs discourse needs to be more sophisticated than simple binary propositions, such as source-oriented versus target-focused translations. High-stakes intercultural communication should not be monodirectional and top-down only, and there is not a one-size-fits-all translation strategy. The standardisation norm is no guarantee how it will be received by a heterogeneous readership. A recent survey shows that globally unfavourable views of China have reached historic highs during the COVID-19 pandemic, which, to some extent, suggests that China's standardised translation policies have not helped much in building intercultural trust.

My argument is that trust between different cultures and ideologies can only be facilitated by ongoing dialogues between people. The attempts to standardise translations not only suggest an exclusion of the interpretive possibilities of a text, but also neglect the fact that translators and readers are subject to ideological, contextual and situational constraints. Because many mistranslations are compounded by problems of culture, stereotype and prejudice, the key to promoting high quality communication lies in the way trust is constructed by people in varying situations. If the translator is not perceived as an active mediator between original 


\section{MELBOURNE ASIAREVIEW}

message and end readers - that is, as someone who shows a kind of loyalty to both sides-but rather as a mechanistic instrument beholden to standardised databases without considering social, cultural or interpersonal factors, the translator's creativity and willingness for intercultural mediation is stifled. Translators need to be empowered to have freer roles in intercultural communication to deal with the complexities of real-world texts.

Standardised translation displays some virtues in highly technical domains. However, equivalent terminology alone is not the best approach for high-stakes political discourse, where literal translations may be devoid of critical context. Highquality, trustworthy foreign affairs communication involves recognising that translators are human beings rather than machines, whose translation decisions are embedded in contextual and situational considerations. As a translation researcher, I hope to show translation officials that standardised narratives can be risky and may miss the nuance needed by policymakers communicating with people in other nations and communities.

Image: US Secretary of State Antony Blinken and National Security Advisor Sullivan Meet with CCP Director of the Office of the Central Commission for Foreign Affairs Yang Jiechi and State Councilor Wang Yi, March 18, 2021. Credit: US State Department/Flickr. 